\title{
Stakeholder attitudes towards the use of recombinant technology to manage the impact of an invasive species: Sea Lamprey in the North American Great Lakes
}

\author{
Ronald E. Thresher $[$ - Michael Jones $\cdot$ D. Andrew R. Drake
}

Received: 23 February 2018/Accepted: 12 September 2018/Published online: 9 October 2018

(C) The Author(s) 2018

\begin{abstract}
Several factors, including: (1) on-going difficulties of cost-effectively managing invasive species; (2) recent successes in using recombinant genetics to suppress mosquito populations; and, (3) developments in gene-drive technology, have reinvigorated interest in using genetic biotechnology to manage the impacts of invasive species. However, the extent to which there is 'social license' to develop and use these technologies has not been widely canvassed. We surveyed stakeholders involved directly and indirectly in managing Sea Lamprey (Petromyzon marinus) in the upper North American Great Lakes and a key community group of resource users-recreational fishers-to assess their support and concerns about researching, developing, and
\end{abstract}

Electronic supplementary material The online version of this article (https://doi.org/10.1007/s10530-018-1848-3) contains supplementary material, which is available to authorized users.

R. E. Thresher $(\bowtie)$

SF Tech, 50 Bramble Street, Ridgeway, TAS 7054,

Australia

e-mail: Ronaldethresher@gmail.com

M. Jones

Fisheries Science Center, Michigan State University,

East Lansing, MI, USA

D. A. R. Drake

Great Lakes Laboratory for Fisheries and Aquatic

Sciences, Fisheries and Oceans Canada, 867 Lakeshore

Road, Burlington, ON L7S 1A1, Canada potentially implementing recombinant methods that an expert group assessed as likely to be effective in managing Sea Lamprey in the Great Lakes. Both groups overwhelmingly supported initiating $R \& D$ and, if risks were deemed very low, undertaking steps towards implementation. The key concern expressed by both groups was the risk of impacts to non-target taxa, including valued native populations of Sea Lamprey outside of the Great Lakes. Few respondents expressed opposition based on ethical or moral grounds, which contrasts with previous surveys on the use of recombinant technology in general. The broad support for R\&D into recombinant approaches is likely to reflect trust in the nominated implementing agency (the Great Lakes Fishery Commission), its history of extensive consultation prior to undertaking management actions, and the hope that genetic biocontrol could "solve" the Sea Lamprey problem rather than simply managing it.

Keywords Biotechnology - Genetic biocontrol · Pest management $\cdot$ Risk $\cdot$ Social license

\section{Introduction}

Decisions about whether or how to control established invasive species are challenging because relatively few control tactics can significantly reduce population 
abundance without profound economic costs or collateral damage to ecosystems. One evolving paradigm that holds promise to control a range of invasive species is the manipulation of an organism's genome with biotechnology (i.e., 'genetic control'; HarveySamuel et al. 2017). Although the application of biotechnology has been explored for pest species in agricultural systems, until recently it has rarely been considered as an option for managing invasive species in the wild (e.g., Snow et al. 2005). To date, there have been no field trials using recombinant techniques explicitly for managing an invasive animal, though genetic techniques have been used to locally suppress disease-vectoring populations of the non-native mosquito Aedes aegypti (Alphey, 2014). However, interest in the idea has surged dramatically over the last 5 years, which can be attributed to: (1) the widespread failure of conventional management to deal with a rapidly expanding list of environmentally destructive invasive plants and animals (Keller et al. 2015; Woodford et al. 2016); (2) recent successful releases of genetically modified insects to reduce mosquito populations (Alphey 2014); and (3) widely publicized speculation about the use of gene drives to introduce a genetic construct into populations of wild animals, including invasive species (Esvelt et al. 2014; Hall 2017; Marshall et al. 2017).

Despite considerable research momentum, the degree to which there is 'social license' (Kendall and Ford 2017) to develop and apply genetic biocontrol against invasive species has not been widely canvassed, but is critical for informed decision making around the issue. Thresher and Kuris (2004) and, more recently, Taylor et al. (2017) report generally positive support for the use of recombinant approaches in general among individuals directly involved in managing the impacts of invasive species, whereas Sharpe (2014) reported that focus groups of users and managers, although broadly interested in the concept of genetic biocontrol of pest fish in the Laurentian Great Lakes, were overall not strongly supportive of its application. Thus far, the only formal assessment of wider public attitudes towards genetic biocontrol of an invasive animal species found strong support for research on "daughterless" technology (an inherited gene construct that biases offspring towards males, see Thresher et al. 2014) to manage Common Carp in Australia, but also a strong desire by the public for further consultation and a robust independent risk assessment prior to field trials or implementation (Fisher and Cribb 2005). In contrast, numerous studies have documented and sought to understand social attitudes around the use of genetic technology in other disciplines, such as increased food and energy production and treatment of human disease (Lucht 2015; Blendon et al. 2016). Overall, acceptability tends to correlate positively with perceived societal benefits, negatively with perceived risks, and positively with the degree of trust in the implementing agency (e.g., Amin et al. 2007; Connor and Siegrist 2010). The extent to which these findings apply to genetic biocontrol of invasive species is unclear. Evaluating key stakeholder and broader public acceptability of genetic control is critical not only to establish whether support exists for a given application, but also to identify key elements of concern (e.g., risks to human health; potential for unintended environmental consequences), which can guide whether and where additional research investment is needed.

We use this perspective to evaluate the social licence around potential genetic control of Sea Lamprey (Petromyzon marinus) in the North American Great Lakes. The Sea Lamprey is one of the world's most destructive invasive species. After invading the lakes in the 1930s, it destroyed commercial and recreational fisheries worth millions of dollars and fundamentally altered the structure of lake ecosystems (Smith and Tribbles 1980; Hansen et al. 2016). Currently, Sea Lamprey are controlled by a binational U.S. and Canadian governmental program based principally on biocidal treatment of larvae in nursery areas of tributary rivers, and maintenance of barriers to spawning migrations of adults, at an annual cost exceeding US \$20 million. The former uses a lampricide, 4-nitro-3-(trifluoromethyl) phenol (TFM), that selectively targets Sea Lamprey during their 3-6 year larval (ammocoete) filter-feeding stage (Smith and Tibbles 1980; Brege et al. 2003). When effective, these methods are believed to remove between 95 and $99 \%$ of ammocoetes from treated streams (W. Swink, U.S. Geological Survey, Hammond Bay Biological Station, unpublished data). Barriers prevent adult Sea Lamprey access to large areas of potential spawning habitat (Hunn and Youngs 1980; Lavis et al. 2003). Alternative approaches, such as chemosterilization/ sterile male release programs (Twohey et al. 2003; Bergstedt and Twohey 2007) and pheromone-based attractants and repellents (Li et al. 2003; Johnson et al. 
2009), have yet to demonstrate efficacy as management tools (e.g., Johnson et al. 2013; Dawson et al. 2016). Both lampricides and barriers are also of stakeholder concern regarding non-target effects, raising concerns about the long-term viability of the current program. Lampricide use has been viewed as in conflict with restoration of native Lake Sturgeon (Acipenser fulvescens) populations due to elevated susceptibility of age 0 Sturgeon to TFM until they reach $100 \mathrm{~mm}$ in length (Dobiesz et al. 2018), and with protection of populations of native lampreys that have been recognized as species of conservation concern. Likewise, growing interest in "de-fragmentation" of Great Lakes watersheds to support native fish populations conflicts with the maintenance of barriers to prevent Sea Lamprey spawning (McLaughlin et al. 2003, 2013; Milt et al. 2018). Finally, existing control tactics are poorly suited for cost-effective management of significant Sea Lamprey production in connecting channels between the Great Lakes, such as the St. Clair River between Lake Huron and Lake St. Clair. These issues have led the Great Lakes Fishery Commission (GLFC), a binational organization established to manage Sea Lamprey impacts in the Great Lakes, to explore complementary management options.

Biotechnology could provide such an option, if determined to be cost-effective, of low ecological risk to non-target species, and, importantly, socially acceptable. "Synthetic biology" has been hailed as a possible transformative tool for conservation biology, with potential applications to de-extinction, invasive species management, and environmental remediation, but the field remains nascent, with contentious potential applications (Redford et al. 2013; Corlett 2017). As a first step towards determining the likely acceptability of using biotechnology to manage Sea Lamprey in the Great Lakes, we surveyed "stakeholder" and "community" (as defined by the Committee on Gene Drive Research in Non-Human Organisms 2016) attitudes towards six recombinant options (see Box 1) that a panel of experts, supported by simulation models, identified as likely to be feasible and effective (for details of the options and the assessment process, see Thresher et al. 2018). We used these surveys to assess attitudes towards the use of recombinant technology in general to control Sea Lamprey, and in particular, to parse levels of support for, and concerns about, the very different recombinant approaches potentially available to lake managers. The results of our surveys, though specific to a particular species, problem, and region, cover a sufficiently wide range of genetic options that they are likely to be informative for current dialogue about the use of recombinant technology to help solve the problems caused elsewhere by invasive species.

\section{Methods}

Two on-line surveys were conducted (SurveyMonkey Inc., San Mateo, CA, USA, www.surveymonkey. com). Participants were selected following extensive consultation with the GLFC, and targeted two key groups: "stakeholders"-professional state, provincial, federal, and tribal biologists, fishery managers, GLFC Commissioners and staff, scientists, and Canadian and U.S. members of the GLFC citizen advisory groups - as well as the Canadian and U.S. Great Lakes "fishing community". The former are all involved directly or indirectly in managing Sea Lamprey in the Great Lakes, whereas fishers constituted resource users who would be broadly familiar with Sea Lamprey impacts and the ecology of the lakes, including on-going efforts to manage the problem, but not directly connected with the GLFC and its activities. Most of the fishing community respondents were avid recreational fishers. The degree of support by professionals and citizen advisors involved in lake management and by a representative, engaged segment of the public was seen as critical information for the GLFC to determine whether to encourage research and development of genetic biocontrol of Sea Lamprey in the Great Lakes, prior to wider consultation with the public at large. With the exception of a few scientists, none of the survey participants had backgrounds in biotechnology beyond basic information gleaned from popular media. The stakeholder survey was conducted in March and April 2017 with a response rate of $73 \%$ (95 returns from 131 individuals contacted). The fishing community survey was conducted in August and Sept. 2017, with a response rate of $51 \%$ (49 of out 96 individuals contacted). The same questionnaire was used for both surveys (see Supplemental Material). It consisted of three sections: (1) questions about the respondent's background and their perception of the importance of managing Sea Lamprey; (2) descriptions of each 
Box 1 Summaries of "Focal" genetic biocontrol options, i.e., those judged by an expert panel to be feasible, low risk and likely to be effective when applied against Sea Lamprey in the Larentian Great Lakes, as provided to survey participants. The options are detailed in Thresher et al. (2018)

Heritable (Mendelian) sex ratio drive-available evidence, which needs to be verified with more field data, suggests the Great Lakes population of Sea Lamprey is female biased and determined by population density (smaller population $=>$ more females) The Atlantic population of Sea Lamprey appears to have a sex ratio of approximately $1: 1$, though again this needs further verification. Modelling indicates that releasing small numbers of lampreys even for only for a few years that have and that pass on a genetic construct that results in carriers developing as males irrespective of population density results in a long-term reduction in female numbers and sustained suppression and possibly eradication of the Great Lakes population, with a negligible impact on the native Atlantic population. The approach may require development and at least short-term (10 year) maintenance of an integrated line of genetically modified lampreys, although it may be possible to achieve the same result, though probably over a longer time span, by mass transforming eggs annually for release. Our expert group judged the overall risk of this approach as moderate, based on possible impacts on Sea Lamprey populations outside of the Great Lakes; risks to other organisms, other lamprey species and human health were all judged to be low

Trojan Gene/Male - an inherited construct in Sea Lamprey that increases male attractiveness while decreasing male fertility (ideally causing complete sterility). If large enough numbers of carriers are stocked annually, sterile but "attractive" males cause a longterm reduction in population fecundity and recruitment. Increased male attractiveness could be achieved by increasing male pheromone production, though this needs considerable testing. Approach may require development and maintenance of a breeding colony of genetically modified lampreys, though it may also be possible to achieve results using mass transformation methods. In the latter case, the Trojan Gene approach is similar to the current sterile male release program but with the addition of enhanced male attractiveness. The approach is feasible, but logistically much more challenging in the absence of the enhanced male attractiveness, in which case it is the GM equivalent of the current sterile male program, albeit perhaps more efficient (if large numbers of sterile males can be produced cheaply and easily using mass transformation techniques). Our expert group judged the overall risks of the inherited Trojan Gene approach as low

Development and release of a non-parasitic Sea Lamprey—numerous lamprey species have evolved closely related sympatric pairs of parasitic and non-parasitic species, suggesting a relatively simple genetic "switch" that possibly determines when sexual maturation develops. It may be possible to trigger this switch pre-metamorphosis in Great Lakes Sea Lamprey either in a genetically modified line or through mass transformation. If parasite population sizes are constrained by density-dependent competition at the larval stage (not certain), then release of a heritable non-parasitic form could sustainably reduce numbers of metamorphs of the parasitic form. The magnitude of the reduction would depend on the relative competitiveness of the parasitic and non-parasitic forms and the extent to which the latter can build up high densities in individual drainages. The expert group judged the overall risks of this approach as low to moderate, with the highest risk (still only moderate) being impacts on native lamprey species

Vaccinated Lake Trout/Prey_production and stocking out of lake trout (preferred prey species of Sea Lamprey in the Great Lakes) that carry a gene construct that results in the production of a molecule in their blood or muscle tissues that when consumed by the parasite is lethal to or (less optimally) sterilizes the parasite. Preliminary modelling suggests that even a small percentage of "vaccinated" carriers in the lake trout population could have a major impact on parasite numbers, depending on the effectiveness of the construct and the number of prey attacked by each parasite. The approach probably requires the development of a line of genetically modified lake trout (salmonid genetic transformation techniques are well developed). Released trout could be made sterile, so that the trait does not become permanent in the population (unless this is desired) and could involve trout strains of little value to recreational fishers. The main technical challenge is the identification of molecules that upon ingestion cause either systemic failure in lamprey parasites or, perhaps, inhibit gut/feeding efficiency (causing starvation), without compromising the trout that are carrying them, and that have no impacts on human health. The expert group judged the overall risks of this approach as low to moderate, with the critical proviso that the molecules in the vaccinated lake trout have no effect on human health

Gene-driven sex ratio distortion-this option is similar in objectives to that in Option 1 (heritable sex ratio drive) but relies on new genetic technology - gene drives - to distort lamprey sex ratios. Gene drives, which have recently been highlighted in the media, essentially result in near $100 \%$ inheritance of, for example, a gene construct that causes all offspring to be male, and all of their offspring to be male, and so on. In theory, almost any genetic modification could be "driven" into a population. The main advantage of a gene drive approach is logistical; in theory, the release of even a single genetically modified carrier can lead to the extinction of the population (and even the species globally) irrespective of the population sex ratio. Given that power, there is concern that it may be difficult to ensure that the effects of the drive are limited to the targeted species and population. Gene drives are actively being researched as eradication and control agents against pests globally, such as malaria-carrying mosquitos. The technology is developing rapidly, and it is highly likely the system could be applied to lampreys. The expert group judged the overall risk of this approach as moderately high to high, due mainly to the possible threat to populations of Sea Lamprey outside of the Great Lakes 
Box 1 continued

Sustained release of sterilizing or lethal molecules in nursery drainages-molecular techniques hold promise as cost-effective slow release, species-specific biocides. Molecules released either as micro-encapsulated particles of the correct size to be ingested by filter-feeding ammocoetes or produced by genetically modified algae or bacteria in nursery drainages could result in long-term accumulation of a lethal, sex determining or sterilizing agent in ammocoetes with a large and cost-effective flow-on effect to parasite population numbers. Micro-encapsulated particles could be dispersed manually, or slow-released in the form of slow dissolving blocks placed into drainage headwaters. A possibly more efficient method of distribution is to genetically modify an alga or bacterium present in the drainages, that are naturally fed upon by the ammocoetes, to produce the biocide. Methods for genetically modifying algae and bacteria are very well developed. The assumption is that release of any genetically modified algae or bacteria would be permanent. The expert group judged the overall risks of this approach as moderately high, due to possible effects on native lamprey populations and, if released as a genetically modified alga or bacterium, on lamprey populations outside of the Great Lakes

recombinant 'focal option' (see Box 1), including a summary sentence of the risk of each as determined by a scientific panel of experts, followed by a) questions regarding the respondent's level of support for undertaking R\&D on that option and for beginning a consultative process that could lead to its' implementation in the Great Lakes ecosystem, b) a checklist of generic objections (e.g., factors related to cost, ethics, whether other Sea Lamprey control options might become available, risks to human health), along with the opportunity to elaborate on "other" objections; and (3) a free-form section soliciting comments on any subject relevant to the issue, but in particular reasons why the respondent favoured or opposed the use of biotechnology to manage Sea Lamprey in the Great Lakes. Although the respondsents were free to comment on technical aspects of each option, including possible costs of development and implementation, the background material did not focus on these on the basis that we sought to elicit the extent of broad support or opposition to each option with getting mired in logistical and technical issues.

Non-parametric statistics were used to analyse the data, using Statview. Regression tree analysis (De'ath and Fabricius 2000), using the R-package 'tree' (Ripley 2016), was used to identify key concerns among respondents that distinguished between those supporting and those opposing the use of biotechnology to manage Sea Lamprey.

\section{Results}

Analysis of survey responses indicated that $84.7 \%$ of the stakeholders and $95.9 \%$ of the fishing community supported or strongly supported undertaking $R \& D$ on one or more recombinant options for managing Sea Lamprey; for undertaking steps towards possible implementation, the figures were $86.3 \%$ and $95.9 \%$ (Fig. 1a, b; detailed results are provided in the Supplemental Material). Among stakeholders, there was widespread support across all respondent groups (e.g., lake manager, fishery biologist, academic scientist, GLFC citizen advisor) (differences among groups for R\&D Kruskal-Wallis $\mathrm{H}=5.86$, not significant), across all age groups (pooled by decade), and irrespective of years of professional experience (for both, Spearman rank correlations against level of support were not significant). Correlations with age and years of experience (as a fisher) were also not significant for the fishing community; there were too few non-recreational fishers in the survey to warrant analysis based on respondent type. Stakeholders and fishers also both broadly supported the use of genetic technology irrespective of whether they thought new management options were needed for the pest or how important they perceived control of Sea Lamprey in the Great Lakes.

Reasons for opposition or concern spanned the full range we provided (see Supplemental Material), but three were most widespread for both stakeholders and the fishing community: effects on non-target species and populations, the adequacy of safeguards for $R \& D$ and implementation, and insufficient knowledge to be comfortable with the idea (Fig. 1c). Concerns ranked similarly for the two surveyed groups (Spearman rank test, $p=0.04$ ). Regression tree analyses indicated that for both undertaking $\mathrm{R} \& \mathrm{D}$ on recombinant options as a whole and for possible implementation, concerns about non-target impacts was the best predictor of poor support, followed by concerns about the adequacy of safeguards and costs (Fig. 2). Group identity, 
Fig. 1 Levels of support for R\&D (a) and possible implementation (b) of one or more recombinant approaches for managing Sea Lamprey in the Great Lakes, among stakeholders and the fishing community (see text for definitions). $\mathrm{SO}=$ Strongly oppose; $\mathrm{O}=$ oppose MO = Mildly oppose; $\mathrm{N}=$ Neutral; MS = Mildly support; $\mathrm{S}=$ Support; SS = Strongly support. C. Distribution of concerns (see Table 1) indicated by GLFC stakeholders and the fishing community with regard to R\&D on genetic biocontrol of Sea Lamprey. The distributions with regard to possible implementation were essentially identical. The ranking of concerns does not differ between the two groups (Spearman rank rho $=0.71, p=0.04$ )
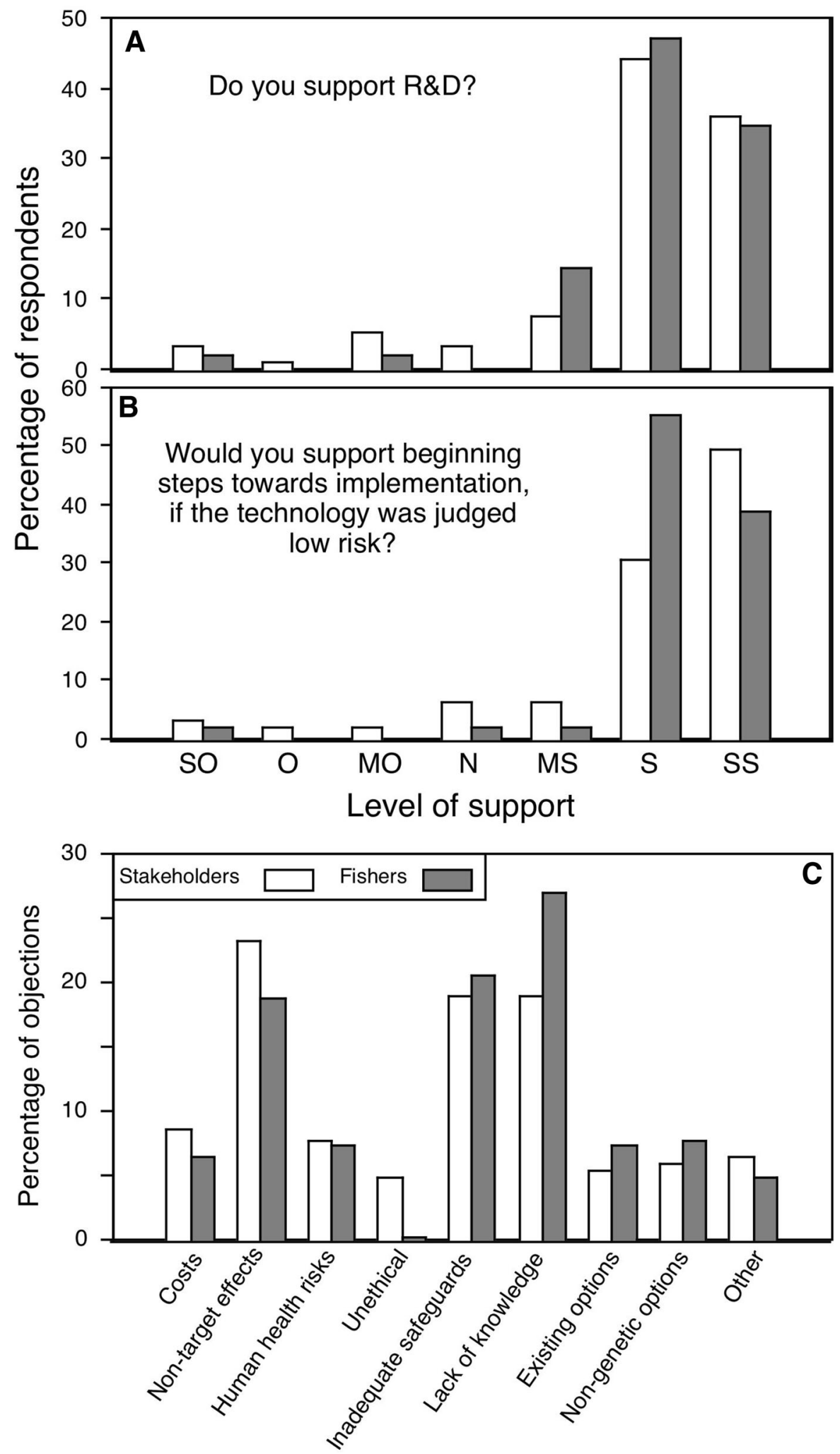
Fig. 2 Results of regression trees for stakeholders and fishers, pooled, identifying factors predictive of support/ opposition for R\&D (a) and starting a process towards possible implementation (b) within respondents that did not Strongly Support each action. Numeric values are mean levels of support (where $\mathrm{SO}=1, \mathrm{O}=2$, $\mathrm{MO}=3, \mathrm{~N}=4, \mathrm{MS}=5$, $\mathrm{S}=6$ ) and node labels indicate survey responses. The model explained $35 \%$ of the variance in the level of support for R\&D and $30 \%$ for implementation. The best predictor of support level in both analyses was the concern about impacts on non-target organisms, followed by the adequacy of safeguards and costs, and, at lower levels of predictability, availability of other options and lack of information

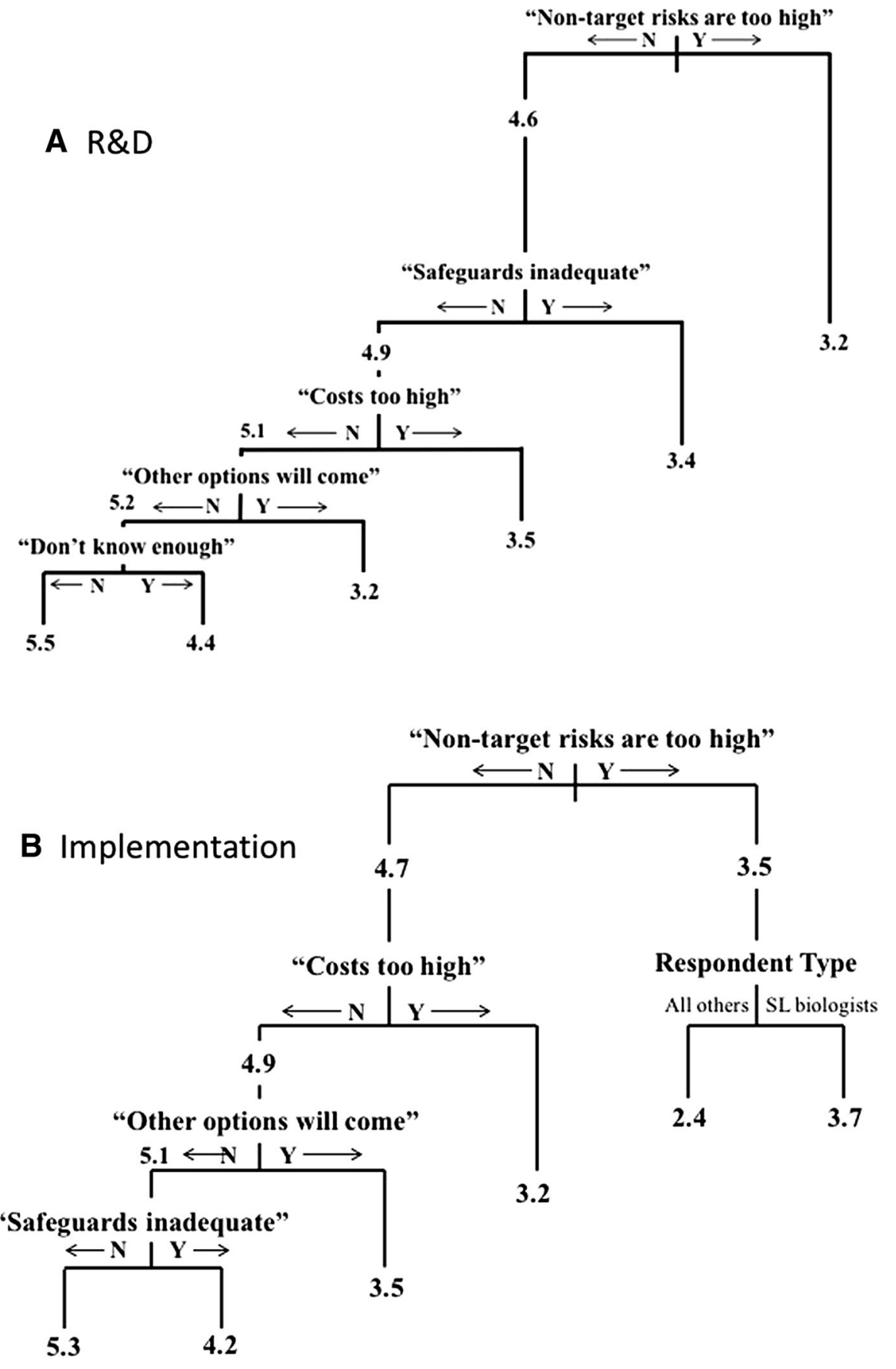

as defined above (stakeholders versus fishers), was not a significant predictor of level of support for either R\&D or implementation. Few respondents identified concerns other than those that fit the broad categories we suggested. The reasons given for opposition differed widely depending on the specific option being considered (see below), but overall concerns ranked similarly for stakeholders and the fishing community (Fig. 1c). Concerns about risks to human health as a result of the recombinant options were not widespread ( $8.1 \%$ of all listed concerns, both surveys pooled), though very concentrated on two options (vaccinated 
prey and a synthetic larval biocide). Ethical concerns about the use of the technology were also not widespread (3.8\% of all listed concerns), identified as an issue least often by both stakeholders and the fishing community. Nonetheless, for every option at least five respondents checked ethical issues as a reason for concern. In the free-form comments section of the survey, two stakeholders strongly stated moral and ethical objections to the use of any recombinant approach. Among the fishers, the most negative respondent stated opposition to any genetic modifications of fishes and/or plants. Reflecting this, among all respondents, $6.2 \%$ opposed $\mathrm{R} \& \mathrm{D}$ on any of the recombinant approaches suggested, and $4.1 \%$ opposed initiating a process towards implementation even if the options were judged low risk.

Levels of support broken down by focal option are summarized in Fig. 3 and Table 1. Support was widespread and positive for three options, equally divided for a fourth ("vaccinated prey"), and negative for a synthetic larval biocide and the use of a gene drive to distort Sea Lamprey sex ratios. The widest support by both stakeholders and fishers was for a Mendelian control option driven by density-dependent sex determination in Sea Lamprey (see Box 1). Results indicated that $82.8 \%$ of stakeholders supported researching and developing this option, and $82.6 \%$ supported its possible implementation. Support among the fishing community was similar $-83.7 \%$ for R\&D and $91.8 \%$ for implementation. In contrast, only about a quarter of respondents supported research on a recombinant larval biocide (27.8 and $25 \%$ for stakeholders and fishers, respectively). Across all options, support levels by stakeholders and the fishing community correlated very highly (Spearman rank test, $p<0.02$ for both $\mathrm{R} \& \mathrm{D}$ and implementation). The major outlier was "vaccinated prey"-a control program based on genetically modifying a lamprey's prey species so as to kill or sterilize the feeding Sea Lamprey. Stakeholders were split evenly with regard to researching this option (50\% support), whereas fishers were broadly opposed to it ( $31 \%$ support). The major reasons given for opposition were similar for the two groups (insufficient knowledge to be comfortable with the idea, too much risk to humans, and not confident that adequate safeguards will be in place), though, interestingly, human risks were highlighted about half as frequently among fishers $(24.4 \%$ of respondents) than among stakeholders (47.9\%)
(Table 1). The costs of project development, ethical issues, the potential availability of non-genetic options, and the perception that existing methods for Sea Lamprey control are adequate were not chosen frequently as concerns for any of the six focal options. Impacts on non-target populations and species was a widespread concern only for options based on synthetic biocides, a gene drive, and development of a non-parasitic Sea Lamprey; concerns about the adequacy of safeguards was widespread across all options; and, as noted above, those regarding human health risks were concentrated on vaccinated prey and the synthetic biocide. "Other" reasons for opposition were infrequently provided, but included concern about the effects of recombinant genes on the integrity of the Sea Lamprey genome and whether lampreys stocked to implement a control program might increase overall environmental impacts of the species, at least in the short term.

Support for R\&D and, to a lesser extent, implementation, tended to be bimodal among stakeholders, but not among the fishing community. The bimodality was most conspicuous with regard to the use of a sexratio distorting gene drive: $40 \%$ of respondents opposed or strongly opposed R\&D on gene drives, whereas $30 \%$ supported or strongly supported it. The bimodality shifted in favour of gene drives $33 \%$ opposed or strongly opposed vs $39 \%$ supporting or strongly supporting) when respondents were asked about possible implementation, with the proviso that "the option proves feasible and risks minimal". Among those opposed to or only weakly supportive of the gene drive option, the overwhelming reason given was the risk to non-target species and populations (79.1\% of respondents), followed by lack of confidence in safeguards (55.9\%) and, more distantly, lack of knowledge to be comfortable with the idea (33.8\%) (Table 1). Support for a gene drive was also low among the fishing community, but less polarized, with the same three reasons given for opposition. Similar patterns (bimodal support levels, claims of inadequate information associated with opposition, and concerns about safeguards) were evident for the other broadly opposed option-synthetic larval biocides. For both options, low correlations between unfamiliarity with the technology and opposition to it makes it uncertain whether or not additional information would affect support levels (rank correlations between support and the frequency with which lack of 


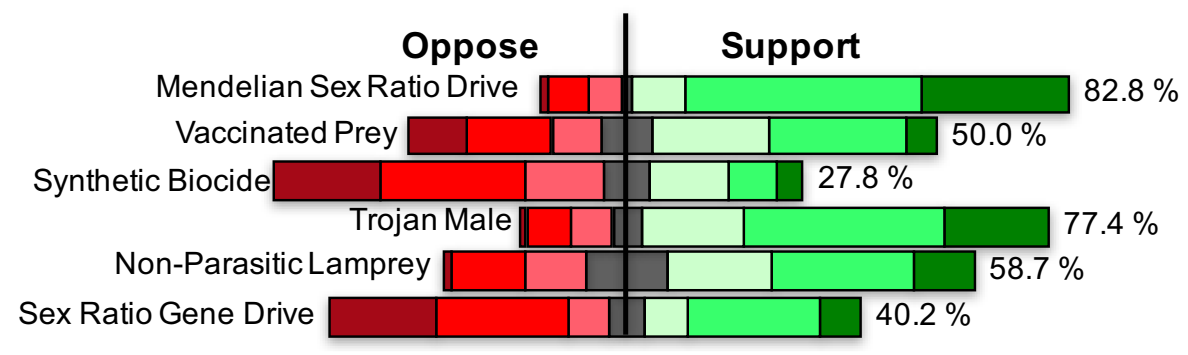

Fig. 3 Distribution of stakeholder levels of support for R\&D on six focal recombinant options for managing Sea Lamprey in the Great Lakes. For details about each option, see Box 1 and Thresher et al. (2018). Colours indicate the seven levels of

Table 1 (a) Number of times a concern was indicated by any one of the 95 respondents to Survey 1 (Stakeholders) with regard to one of the six focal options (see Box 1). (b) Number support by respondents from strongly opposed (dark red) to strongly support (dark green); brown indicates no preference for support or opposition. Figures to the right indicate the percentage of respondents supporting $R \& D$ for each option

of times a concern was indicated by any one of the 49 respondents to Survey 2 (Fishing community) with regard to one of the six focal options (see Box 1)

\begin{tabular}{|c|c|c|c|c|c|c|c|}
\hline Concerns & $\begin{array}{l}\text { Sex ratio } \\
\text { drive }\end{array}$ & $\begin{array}{l}\text { Trojan } \\
\text { male }\end{array}$ & $\begin{array}{l}\text { Non-parasitic Sea } \\
\text { Lamprey }\end{array}$ & $\begin{array}{l}\text { Vaccinated } \\
\text { prey }\end{array}$ & $\begin{array}{l}\text { Gene } \\
\text { drive }\end{array}$ & $\begin{array}{l}\text { Synthetic larval } \\
\text { biocide }\end{array}$ & Total \\
\hline
\end{tabular}

(a)

\begin{tabular}{|c|c|c|c|c|c|c|c|}
\hline Costs & 3 & 20 & 14 & 21 & 7 & 12 & 77 \\
\hline Non-target effects & 15 & 13 & 38 & 22 & 54 & 66 & 208 \\
\hline Human health impacts & 2 & 2 & 2 & 34 & 5 & 24 & 69 \\
\hline Unethical & 7 & 5 & 8 & 7 & 9 & 7 & 43 \\
\hline Inadequate safeguards & 19 & 19 & 19 & 30 & 38 & 43 & 168 \\
\hline Lack of knowledge & 26 & 22 & 31 & 34 & 23 & 32 & 168 \\
\hline $\begin{array}{l}\text { Existing methods } \\
\text { adequate }\end{array}$ & 8 & 9 & 6 & 8 & 9 & 8 & 48 \\
\hline $\begin{array}{l}\text { Other options will be } \\
\text { available }\end{array}$ & 8 & 7 & 9 & 10 & 11 & 8 & 53 \\
\hline Other & 5 & 14 & 13 & 14 & 7 & 4 & 15 \\
\hline Total & 93 & 111 & 140 & 180 & 163 & 204 & \\
\hline \multicolumn{8}{|l|}{ (b) } \\
\hline Costs & 2 & 2 & 5 & 8 & 3 & 1 & 21 \\
\hline Non-target effects & 4 & 0 & 8 & 3 & 19 & 27 & 60 \\
\hline Human health impacts & 2 & 0 & 0 & 14 & 2 & 5 & 23 \\
\hline Unethical & 0 & 0 & 0 & 1 & 0 & 0 & 1 \\
\hline Inadequate safeguards & 4 & 7 & 12 & 19 & 10 & 14 & 66 \\
\hline Lack of knowledge & 6 & 9 & 15 & 18 & 14 & 25 & 87 \\
\hline $\begin{array}{l}\text { Existing methods } \\
\text { adequate }\end{array}$ & 4 & 3 & 3 & 5 & 6 & 2 & 23 \\
\hline $\begin{array}{l}\text { Other options will be } \\
\text { available }\end{array}$ & 2 & 2 & 5 & 7 & 4 & 5 & 25 \\
\hline Other & 2 & 3 & 1 & 6 & 1 & 2 & 15 \\
\hline Total & 26 & 24 & 49 & 81 & 55 & 91 & \\
\hline
\end{tabular}

knowledge was listed as a concern were not significant for both options and for both R\&D and Implementation). However, lack of knowledge was associated with concerns about human health risks for the biocide (Mann-Whitney U test, $p<0.001$ ), which suggests 
scope for greater support if more detail is provided about the molecules involved.

\section{Discussion}

Several conclusions that can be drawn from our analyses are not surprising, e.g., that health issues are of concern for options that could involve the human food chain (e.g., Siegrist 2008), and that risks to nontarget populations are of paramount concern for gene drives (e.g., Harmon 2016). Other results, however, are perhaps more surprising. First, roughly $90 \%$ of respondents supported researching and ultimately using some form of recombinant technology to manage an invasive species. This level of support was evident across the full spectrum of respondent types, age, experience with the resource, and perceived need for alternative control tactics. We suspect the high levels of support reflects a widespread appreciation of the historical and on-going impacts of Sea Lamprey on lake ecosystems and of the difficulties of managing the species with current technology. It is also possible that biotechnology is viewed as a way to "solve" rather than manage, the Sea Lamprey problem. This high level of support is consistent with a recent survey of stakeholders in New Zealand similarly engaged in invasive species management (Taylor et al. 2017), but contrasts with a previous study involving a similar demographic group on the acceptability of genetic biocontrol for managing invasive fishes in the Great Lakes in general (Sharpe 2014). The reasons for the differences are not clear, but could include the nature of the consultation process (surveys vs focus group discussions) and the degree of trust in the initiating agency (Frewer et al. 1999; Connor and Siegrist 2010; Sharpe 2014). The GLFC has long-standing, well publicized, and extensive processes for participatory public engagement in decision making. In our case, we also presented the surveyed participants with a very specific list of options coupled with an assessment of their ecological and social risks as judged by an independent science panel, which may have fostered a more nuanced consideration of risks, even at the lay level, against which the benefits of reducing Sea Lamprey impacts could be assessed. In that regard, our results parallel those of Fisher and Cribb (2005), which, although targeting the general Australian public, found strong support for $\mathrm{R} \& \mathrm{D}$ on the single, well described recombinant option ("daughterless technology") presented.

Second, there are numerous and diverse ways that recombinant genetics can be used to manage invasive species, but not all are equally acceptable to stakeholders. Although a small minority objected to all options on ethical and moral grounds, the majority of respondents clearly distinguished between the options tabled, strongly supporting some but questioning others. Supported options were those least likely to have an adverse impact on non-target species. This was not coupled with concerns about a lack of knowledge, which suggests a significant burden-ofproof issue for recombinant techniques that could affect non-target species and populations (e.g., synthetic biocides, gene drives and genetically modified self-disseminating vectors). Notably, all but one option was supported at essentially identical levels by the stakeholder group and by a lay community group. The exception-genetically modifying fish attacked by Sea Lamprey-was not strongly supported by either group, but less so by recreational fishers. Reasons given for lack of support were primarily a lack of information and possible human health risks, which reflects concerns that the preferred prey species for Sea Lamprey, and hence the best species to modify to manage them (e.g., Lake Trout, Cisco), are prized by recreational and commercial fishers. These results also indicate a potentially high level of risk aversion when prized species are the potential bearers of unintended effects due to genetic modification. Professional biologists and lake/fishery managers were less strongly opposed to implementation of recombinant approaches based on their potential non-target effects than, as a group, fishers and citizen advisors to the GLFC. The difference could reflect a better understanding of possible interactions between the genetic program and lake ecosystems among biologists and managers, less trust by fishers and citizen advisors of the risk levels assigned to each recombinant option by our independent expert panel, or a general wariness of the public about recombinant technology for managing fishery issues.

Finally, among stakeholders and the resource users we surveyed, very few opposed research and possible implementation of recombinant options on the basis of moral and ethical grounds. This is in striking contrast to the results of studies that followed the early 
applications of recombinant technology (primarily involving food production, e.g., Rolland 1995; Sadler and Zeidler 2004). While ethical and moral objections will inevitably remain the critical factor for some stakeholders, which needs to be incorporated into any consultative process, the small fraction of stakeholders holding these positions suggests that much of the discussion and decision-making will be based on technical issues rather than social ones per se. The extent to which this is generalizable to the wider public is not known. While our surveys demonstrate support for 'genetic control' by communities that will benefit most strongly from their application (e.g., those with professional and recreational ties to the Great Lakes fishery), broader canvassing of the publicat-large and targeted surveys of additional key groups, such as indigenous communities, is an important avenue for follow-up research, as past work indicates that viewpoints between stakeholders and the public can differ for even simple fishery management decisions (Whitemarsh and Palmieri 2009). Nonetheless, we suspect that support for recombinant approaches by a transparently consultative managing agency, such as the GLFC, and a key, closely involved community group-recreational fishers-is likely to have a significant flow-on effect to acceptability by the broader community.

Acknowledgements We thank all of those who took the time to respond thoughtfully to our on-line surveys. We also thank J. Burnett, D. McCauley, M. Twohey, M. Docker, C. Krueger, H. Qui, A. Muir and N. Johnson for providing expert advice on the risks of the recombinant options, and the Great Lakes Fishery Commission and staff and the GLFC Sea Lamprey Control Board for feedback on the project as it evolved. This work was supported by a grant from the Great Lakes Fishery Commission. This is publication 2018-18 of the Quantitative Fisheries Center at Michigan State University (Grant No. 2016_JON_54054).

Open Access This article is distributed under the terms of the Creative Commons Attribution 4.0 International License (http:// creativecommons.org/licenses/by/4.0/), which permits unrestricted use, distribution, and reproduction in any medium, provided you give appropriate credit to the original author(s) and the source, provide a link to the Creative Commons license, and indicate if changes were made.

\section{References}

Alphey L (2014) Genetic control of mosquitoes. Ann Rev Entomol 59:205-224
Amin L, Jahi JM, Nor ARM, Osman M, Mahadi NM (2007) Public acceptance of modern biotechnology. Asia Pac J Mol Biol Biotechnol 15:39-51

Bergstedt RA, Twohey MB (2007) Research to support sterilemale-release and genetic alteration techniques for sea lamprey control. J Great Lakes Res 33(Special Issue 2):48-69

Blendon RJ, Gorski MT, Benson JM (2016) The public and the gene-editing revolution. N Engl J Med 374:1406-1411

Brege DC, Davis DM, Genovese JH, McAuley TC, Stephens BE, Westman RW (2003) Factors responsible for the reduction in the quantity of the lampricide, TFM, applied annually in streams tributary to the Great Lakes from 1979 to 1999. J Great Lakes Res 29(Suppl. 1):500-509

Committee on Gene Drive Research in Non-Human Organisms: Recommendations for Responsible Conduct (2016) Gene drives on the horizon: advancing science, navigating uncertainty, and aligning research with public values. National Academies Press, Washington

Connor M, Siegrist M (2010) Factors influencing people's acceptance of gene technology: the role of knowledge, health expectations, naturalness, and social trust. Sci Comm 32:514-538

Corlett RT (2017) A bigger toolbox: biotechnology in biodiversity conservation. Trends Biotechnol 35:55-65

Dawson HA, Jones ML, Irwin BJ, Johnson NS, Wagner CM, Szymanski M (2016) Management strategy evaluation of pheromone-baited trapping techniques to improve management of invasive sea lamprey. Nat Resour Model 29:448-469

De'ath G, Fabricius KE (2000) Classification and regression trees: a powerful yet simple technique for ecological data analysis. Ecology 81(11):3178-3192

Dobiesz NE, Bence JR, Sutton T, Ebener M, Pratt TC, O'Connor LM, Steeves TB (2018) Evaluation of sea lamprey-associated mortality sources on a generalized lake sturgeon population in the Great Lakes. J Great Lakes Res 44:319-329

Esvelt KM, Smidler AL, Catteruccia F, Church GM (2014) Concerning RNA-guided gene drives for the alteration of wild populations. eLife 3:e03401. https://doi.org/10.7554/ elife.03401

Fisher N, Cribb J (2005) Monitoring community attitudes to using gene technology methods (daughterless carp) for managing common carp. Cooperative Research Center for Pest Animal Control, Valuemetrics

Frewer LJ, Howard C, Hedderley D, Shepherd R (1999) Reactions to information about genetic engineering: impact of source characteristics, perceived personal relevance, and persuasiveness. Public Underst Sci 8:35-50

Hall SS (2017) Could genetic engineering save the Galapagos? Sci. Amer. www.scientificamerican.com/article/couldgenetic-engineering-save-the-gal-aacuote-pagos/. Accessed 2 Nov 2017

Hansen MJ, Madenjian CP, Slade JW, Steeves TB, Almeida PR, Quintella BR (2016) Population ecology of the Sea Lamprey (Petromyzon marinus) as an invasive species in the Laurentian Great Lakes and an imperiled species in Europe. Rev Fish Biol Fish 26:509-535

Harmon A (2016) Panel endores "Gene drive' technology that can alter entire species. New York Times, 8 June, 2016. 
www.nytimes.com/2016/06/09/science/nationalacademies-sciences-gene-drive-technology.html?rref= collection $\% 2$ Fbyline $\% 2$ Famy-harmon\&action= click\&contentCollection=undefined \&region= stream \&module=stream_unit $\&$ version $=$ search \&contentPlacement $=3 \&$ pgtype $=$ collection

Harvey-Samuel T, Ant T, Alphey L (2017) Towards the genetic control of invasive species. Biol Invasions 19:1683-1703

Hunn JB, Youngs WD (1980) Role of physical barriers in the control of sea lamprey (Petromyzon marinus). Can J Fish Aquat Sci 37:2118-2122

Johnson NS, Yun S-S, Thompson HT, Chio J, Li W (2009) A synthesized pheromone induces an upstream movement in female sea lampreys and summons them into traps. Proc Nat Acad Sci (U S) 106:1101-1108

Johnson NS, Siefkes MJ, Wagner CM, Dawson HA, Wang H, Steeves TB, Twohey M, Li W (2013) A synthesized mating pheromone component increases adult sea lamprey (Petromyzon marinus) trap capture in management scenarios. Can J Fish Aquat Sci 70:1101-1108

Keller RP, Cadotte MW, Sandiford G (2015) Invasive species: a global problem in need of a global solution. University of Chicago Press, Chicago

Kendall D, Ford RM (2017) The role of social license in conservation. Conserv Biol 0:1-3

Lavis DS, Hallett A, Koon EM, McAuley TC (2003) History of and advances in barriers as an alternative method to suppress sea lampreys in the Great Lakes. J Great Lakes Res 29(Suppl. 1):362-372

Li W, Siefkes MJ, Scott AP, Teeter JH (2003) Sex pheromone communication in Sea Lamprey: implications for integrated management. J Great Lakes Res 29(Suppl 1):85-94

Lucht JM (2015) Public acceptance of plant biotechnology and GM crops. Viruses 7:4254-4281

Marshall JM, Buchman A, Sanchez HM, Akbari OS (2017) Overcoming evolved resistance to population-suppressing homing-based gene drives. Sci Rep 7:3776. https://doi.org/ 10.1038/s41598-017-02744-7

McLaughlin RL, Marsden J, Hayes DB (2003) Achieving the benefits of sea lamprey control while minimizing effects on nontarget species: conceptual synthesis and proposed policy. J Great Lakes Res 29(Suppl. 1):755-765

McLaughlin RL, Smyth ERB, Castro-Santos T, Jones ML, Koops MA, Pratt TC, Velez-Espino L (2013) Unintended consequences and trade-offs of fish passage. Fish Fish $14: 580-604$

Milt AW et al (2018) Minimizing opportunity costs to aquatic connectivity restoration while controlling an invasive species. Conserv Biol 32:894-904

Redford KH, Adams W, Mace GM (2013) Synthetic biology and conservation of nature: wicked problems and wicked solutions. PLoS Biol 11(4):e1001530. https://doi.org/10. 1371/journal.pbio. 1001530

Ripley B (2016) Tree: classification and regression trees. R package version 1.0-37. https://CRAN.R-project.org/ package=tree. Accessed 16 Oct 2017

Rolland BE (1995) The Frankenstein syndrome. Cambridge Univ. Press, Oxford

Sadler TD, Zeidler DL (2004) The morality of socioscientific issues: construal and resolution of genetic engineering dilemmas. Sci Educ 88:4-27

Sharpe LM (2014) Public perspectives on genetic biocontrol technologies for controlling invasive fish. Biol Invasions 16:1241-1256

Siegrist M (2008) Factors influencing public acceptance of innovative food technologies and products. Trends Food Sci Technol 19:603-608

Smith BR, Tibbles JJ (1980) Sea lamprey (Petromyzon marinus) in Lakes Huron, Michigan, and Superior: history of invasion and control 1936-78. Can J Fish Aquat Sci 37:1780-1801

Snow AA, Andow DA, Gepts P, Hallerman EM, Power A, Tiedje JM, Wolfenbarger LL (2005) Genetically engineered organisms and the environment: current status and recommendations. Ecol Appl 15:377-404

Taylor HR, Drussex N, van Heezik Y (2017) De-extinction needs consultation. Nat Ecol Evol 1:0198. https://doi.org/ 10.1038/s41559-017-0198

Thresher RE, Kuris A (2004) Options for managing invasive marine species. Biol Invasions 6:295-300

Thresher RE, Van de Kamp J, Campbell G, Grewe P, Canning M, Barney M, Bax NJ, Dunham R, Su B, Fulton W (2014) Sex-ratio-biasing constructs for the control of invasive lower vertebrates. Nat Biotechnol 32:424-427

Thresher RE, Jones M, Drake DAR (2018) Evaluating active genetic options for the control of Sea Lamprey (Petromyzon marinus) in the Laurentian Great Lakes. Can J Fish Aquat Sci. https://doi.org/10.1139/cjfas-2018-0153

Twohey MB, Heinrich JW, Seelye JG, Fredricks KT, Bergstedt RA, Kaye CA, Scholefield RJ, McDonald RB, Christie GC (2003) The sterile-male-release technique in Great Lakes sea lamprey management. J Great Lakes Res 29(Suppl. 1):410-423

Whitemarsh D, Palmieri MG (2009) Social acceptability of marine aquaculture: the use of survey-based methods for eliciting public and stakeholder preferences. Mar Policy 33:452-457

Woodford DJ, Richardson DM, MacIsaac HJ, Mandrak NE, van Wilgen BW, Wilson JRU, Weyl OLF (2016) Confronting the wicked problem of managing biological invasions. NeoBiota 31:63-86 